\title{
Art of Teaching with Case Studies
}

\author{
Damber Singh Kharka
}

Officiating Chief Executive Officer/Director, Druk Holding and Investments, Thimphu, Bhutan

\begin{abstract}
In this paper I have shared some of my experiences on how to handle case studies in teaching with the intent to facilitate more discussions during our meeting over the two day conference on "research informed teaching" at Samtse College of Education organized by the Royal University of Bhutan in October 2014. We know that case studies are stories used as knowledge and skill transfer vehicles by which a lot of real life scenario is brought into the classroom to be discussed by the students and instructors. How we use case studies depends upon the objectives and the format of the course. My experience suggest that if it is a regular university dictated course with a strict timetable (one hour period everyday per subject) with pre-identified contents and has a large class size, it is not normally possible or at least not meaningfully efficient to go beyond the use of simple cases that will only help to illustrate the subject concepts and demonstrate a few practical aspects. However, if the class is smaller and the course is more discussion based with properly designed sessions, we choose to use cases through complex analysis thereby guiding the students in a step-wise fashion in the analysis of relevant information, problem identification and option evaluation. Whatever may be the format of the course or the class in which we use case studies, it is important that we, as case teachers, prepare ourselves well and know all the issues involved in the case, prepare questions in advance and prompt discussions and debate in the class, and anticipate where students might run into problems. Needless to mention that we encounter within the class, few or even all students finding themselves out of place when case studies are used; it particularly true in the Bhutanese situation as our teaching and learning system is historically predominant with the traditional lecture method. To overcome such problems, it is essential to prepare students for case based learning methods. We must know about our students' backgrounds in advance so that we can productively draw on their areas of expertise, experiences and personalities to enhance the discussion and enrich learning across the board as facilitators rather than acting as a traditional teacher.
\end{abstract}

KEY WORDS: Case selection, trainers' preparedness, case facilitation, discussion and students' performance evaluation.

\section{Council for Innovative Research}

Peer Review Research Publishing System

\section{Journal: International Journal Of Management \& Information Technology}

Vol. 10, No 9

editorsijmit@gmail.com

www.jimit.com 


\section{INTRODUCTION}

When we talk about case studies, we see it in two ways. One, we talk about a research case that aims to reveal in-depth analysis on a relatively smaller unit of research or more focused research subject that demonstrates or refines theories. The other type of case study is about a teaching case that basically narrates a story about enterprise, society, individual, etc. that provides information on what happened, who are the actors, what are the actors confronted with, how it happened and so on. Like research cases, a teaching case will also mostly be in a formal written format, but a newspaper article, movie clip, TV news story or interviews can form good substitutes for written cases for teaching purposes. Whatever the format may be, teaching cases illustrate fighting issues and problems, reflect theoretical frameworks, underline assumptions and principles, and reveal realistic complexities and uncertainties for facilitation of classroom discussion. In this paper, a mention of a case anywhere in my writing would mean a teaching case.

This paper describes very briefly the importance of using cases in classrooms/training halls and the way cases are to be handled for effective learning. Largely based on what experienced teachers/trainers have said and written on case study approach of teaching and given my own experience as a trainer in a management school for over 18 years and as a corporate executive for seven years with exposure in handling cases in the training hall, I attempted to recall wisdom shared by others and share my experience on using cases. Given my own background this note is biased towards handling cases in management classes. However, I obviously think that the process remains largely similar in

whichever discipline we may use case studies. The basic intend of this paper initially was to facilitate discussions and enrich case developers and users about the process and methodologies of teaching a case at the conference on "research informed teaching" organized by the Royal Bhutan University (RUB) at Samtse College of Education, Bhutan in October 2014. However, as the RUB showed interest in publishing this article in their journal it has been remodeled to suit the requirement.

\section{IMPORTANCE OF USING A CASE STUDY}

If we look at the literature or recall the way we develop or/and use case studies, we understand that it is nothing but a story line that helps us present realistic, complex, and contextually rich situations that often provide a scenario with dilemma, conflict, or problems that one or more of the characters in the story is involved with. It is an effective vehicle by which essential parts of reality that matters are brought into the classroom to be discussed by students and a trainer. Proper use of a case in the classroom grounds the students on facts that are faced in real life situations. As an effective tool of teaching in various disciplines, case studies have gained more and more popularity and become instructional strategy that "bridge the gap between theory and practice and between the academy and the work place" (Barkley, Cross and Major (2005). Case studies generate opportunities for students to distinguish pertinent from peripheral information, get involved in identification of problems, recognizing and articulating positions, evaluating courses of action, arguing different points of view, and formulating strategies. It is a student centered learning method that demonstrates theoretical concepts in an applied setting in contrast to traditional lecture based approach.

Experiences suggest that case method teaching immerses students into practical business situations, force them to think realistically and logically to form up their positions. Students get fully involved in analyzing available information and sometimes face a situation with incomplete information. As students work with analyzing business situations, they are forced to work with time constraints and conflicting goals. The Case study approach is a very powerful tool that forces students to become more responsible for their learning, makes courses relevant to their real needs, empowers them to think critically and sharpens their analytical skills.

Cases method uses real life practical examples in contextualizing theoretical concepts. I have always found that the case approach generated more interactive learning systems, created better opportunity for development of key skills such as communication, working in groups, coming out of shyness for participation and presentation skills. On the whole, students are empowered in problem identification, developing alternative solutions, examining likely cause and effects and take decisions, which are not facilitated so much by the traditional lecture based teaching.Goodenough (1994) states, "In lecturing, success meant that students paid attention, laughed at my jokes, and applauded me. I told them what to learn, and they learned it. ... When I teach now I worry about such questions as whether everyone in the group has participated. Have questions generated energetic (but respectful) controversy? Has the group really pried the case open, created an agenda for further study, and developed a strategy for addressing its own questions?" This statement captures the need, in a nutshell, for moving beyond traditional lecture based teaching.

A traditional teaching approach of pure lecture system is very much a teacher-centered way that makes students much too dependent on teachers. Lecture based teaching focuses on teachers providing all the information, analyzing them in identifying problems and evaluating alternative solutions and finally providing students with the teachers' solution. Cases study on the other hand ensures that students are capable of using information that they have been provided with in the case and forces them to think of and use background knowledge that they may have already studied in their own areas. By exposing them to real situations and asking them to make critical decisions, case studies force students to connect their knowledge and available information with the need to evaluate different options to generate solutions. This process removes a lecturer from the center stage of being the main speaker (most of time the only speaker) to a role of a facilitator thereby reducing too much dependence of students in the learning process (Golich, Boyer, Franko and Lamy- 2000). In a lecture note, it is the teachers' choice about the quantity and scope of information and the analysis to be presented for the consumption of students. In contrast, a teaching note of a case study develops more of a road map, like a decision making tree, that facilitates articulation of perspectives and details on lead questions that help students discover for themselves the content, issues, arguments and concepts embodied within the case. If lectures foster learning by listening and seeing 
what other do in the class, the case approach provides opportunities for learning by doing, the latter of which is generally recognized to be the superior way of acquiring knowledge. A major advantage of teaching with case studies, unlike with lecturing, is that the students are actively engaged in figuring out the concepts and principles that are applied in real life. In a nutshell, case approach develops their skills in problem solving, analytical tools and decision- making.

\section{HOW TO USE CASES IN THE CLASSROOM?}

The first thing in teaching a case is to identify a case itself given the course objective. When you pick a case, you have to keep a number of things in mind. Among them, a few but crucial ones to consider in my view are as follows.

\subsection{SelectingACase}

Firstly, a case facilitator should look at the objective of the course topic that will be discussed in the class and skims cases to identify the one that meets the learning objectives. I remember my very few initial sessions with Prof. Victoria S. Licuanan of the Asian Institute of Management, Manila who organized a week long workshop on case writing and case teaching for the faculty of Royal Institute of Management in 2003. She very categorically told us that if we are selecting a case to meet certain objectives then we should look for a case that is not too long and that does not deal with too many concepts. She said, "lessor the points in the case, better it is". Then she explained that fewer points, fewer themes, fewer questions, fewer issues would lead to more in terms of learning, understanding, and getting into the depth. Often, as case users, we tend to pick a case that has too many issues not really required for the course objective at hand. This will only deviate the learning focus and confuses the learners.

Secondly, one has to be aware of the level of your audience. If the students have not had earlier exposure to case based learning, obviously you should look for a short and simple one that suits the learners' capacity. You need to pick a case so it matches the audience and the course objectives. It may be that the first timers need some coaching on how to read the case rather than getting into deeper analysis. Reading a case is a skill in itself.

Thirdly, if the case is accompanied with additional resources such as teaching notes, it makes the case facilitator's life easier. If you have developed a case yourself you already know 'for whom and for what topics' the case is most appropriate. Most of the time we pick up cases from the case bank, which are prepared by others. In such a situation, you need to see if a case is accompanied with a teaching note that provides hints to the facilitator on for whom and for what topic a particular case could be used. A teaching note provides the process of using it with details on lead questions in order to influence a class into a particular direction as per the learning objective. It also provides a short synopsis on the case subject, the main characters, crucial information, problems and available options. Among all, it indicates decision choice of the options. However, a note is meant only for the facilitator and not for distribution to the students before the case discussion.

Fourth, besides course objectives, it is equally important to consider the class size, course format and the amount of flexibility a trainer has in terms of extending class duration beyond normal university dictated one hour per session type of format in choosing a case. In a very large class size with hourly sessions, we won't be able to use complicated cases that require detail analysis and as such we will be limited tousing simple cases to be worked in groups just to illustrate and enrich the subject concepts and throw few practical aspects.

\subsection{Preparing Students For Case Discussion}

The second thing I consider very crucial is preparing students for the case learning method, particularly if they have not had familiarity with this system. Case studies can be especially effective only if students are prepared before they start discussions. Students are required to read the case and understand concepts or analytical methods embodied in the case. It may be wiser to first prepare students on how to read and analyze a case. There are useful steps in reading a case that may be shared for first timers.

- $\quad$ Step number one is to do a case skimming. It means reading a case completely but quickly just to get a general feel for the case.

- Step number two is to do a careful reading. Here one has to highlight, underline important facts and issues, make note about symptoms and spot problem areas.

We need to clarify to the students that the basic requirement is that they carry the main load and not the teachers. In fact a teacher only plays a facilitating role. So, it is them who should carry out the discussion role whereas the teacher basically provides little tips here and there to direct the discussion towards a desired outcome in line with the learning objectives of the course.

The other requirement in preparing the students is that they should know that they are preparing answers to assignment questions for which normally there is no easy right or wrong answer. They may be asked to make their own choice for a solution to the question but they need to have strong positions for their chosen answer. They should be ready to present their views and be prepared to argue in support of their choice. To be prepared to this level, students need to know the steps involved in case analysis. My own experience as a case teacher comes mostly from the real business case facilitation in a management school. Business cases are mostly generated form real scenarios of companies, organizations, groups and individuals in the business world faced with certain decision challenges. I found that preparing students in case skimming, identifying broad issues, utilization of data from appendices, second time reading in more depth with underlining and making marginal notes, listing key problems, prioritizing problems, identifying options, evaluating options and preparing positions for their selected options have immensely helped in students' learning ability. 
While preparing students one may like to show how students should do the following processes that improve their case analysis skills.

- Conduct a situation audit: synopsis and evaluation of an organization's (case subject) existing situation. This may be conducted by assessing internal and external business environments facing the organization through strength, weakness, opportunity and threat (SWOT) analysis or/and political, economical, social, technological, environmental and legal (PESTEL) analysis in relation to the organizational mandates and objectives. Students may require more information than what is provided in the case itself and may have to make certain assumptions. As long as additional information and assumptions are realistic and explicit, it would only enrich the analysis.

- Use of worksheets that provided key facts, issues and inter-linkages between variables, facts and symptoms has been a useful analytical framework.

- Problem or decision statement: It is very crucial for students to identify the main problem and link it to symptoms, facts and possible causes. Most students and even many experienced managers will face difficulty in this step as we often get confused between symptoms and problems, and correct inter-linkage between symptoms and problems due to multiplicity of such parameters.

- Evaluation of alternative options to address identified problem: This is where students need to prepare their position in terms of supporting their view points with regard to their chosen option/decision for new direction. There is no straight right or wrong answer.

I strongly feel that students need to be prepared in the above steps and processes. If they have done so, then they have really put themselves in the shoes of the decision makers or the main character (protagonist) in the case.

While, given the need to argue for or against certain issues during the class discussion, the risk is that the students may come up with unmanageably long descriptions and put forward so many points. They should be warned that the focus should be mainly on the key issues. Students should know about the learning objectives that the case should ultimately meet. If you try to cover everything in the case, it will take hours or even longer just for one case. Therefore, managing time is one skill that both students and a facilitator should be worrying about. After all, one of the hidden agendas of the case method teaching is developing skill in time management.

\subsection{Trainers Preparedness, Facilitation And Evaluation}

It is a prerequisite for a trainer to have the clarity in mind about relevance of the case to the learning objective and the facilitating process. One has to have the mastery of facts, issues and other materials provided in the case. It is advisable to be prepared for anticipated questions that may arise during the discussion for which students need your support. You have to have your plan as to how you want the discussion to start and where you want it to end and how you are going to evaluate the students' performance. It will be a mistake if you think that a case approach of teaching reduces your workload since your students will be doing most of the talking.

\subsubsection{Plan Your Session To Lead The Case Discussion}

While planning to teach a case, one should have the skills to break or segment the case into pieces. From different segments, one has to identify main issues for discussion given your course objectives. Main issues are those that are controversial or debatable in nature. You will find certain issues where the case analysts will either have a very strong yes or a no answer. As a case facilitator, one should prepare guidelines to prompt arguments in support of both yes and no answers.

The trainer should have a plan to encourage students to follow a systematic approach to their analysis. Facilitation usually starts with bringing out key information of the case that centers on case objectives and desired solutions.

To kick-start the discussion, it is usually practiced that we first focus on easy and less debatable questions that all the students are able to answer confidently. This helps to generate energy in the class. However, some case discussions start by forcing the students to take their positions on a particular issue. Another approach is to ask someone randomly to "open" the case. Opening of the case includes entire analysis, from surfacing out key information, problems, and available options. Some may choose to guide discussion with questions that move students from problem identification to solutions.

Whatever the approach we use, the ultimate aim is to involve as many students as possible while meeting the learning objective. If we are prepared to guide students in surfacing out key information, clarifying and confirming points that are raised, drawing students attention to related points, fostering debate on fighting issues and resolving it smoothly, changing direction of discussion towards learning objectives and stimulating students' thoughts and concepts, I think we will be successful

as case

facilitators. In order to engage all the students, one can divide them into groups, give each group several minutes to discuss a case and then randomly ask any one person in each group to present their answers and reasoning to any question you may like to ask. A trainer should let the groups with contrasting views intellectually fight in the class. In fact, you should already have some sense on how long the debate may last on different segments and accordingly manage time so that each issue is fairly discussed from both the views and at least a fair equity among the groups and individuals in class participation is maintained. It is very essential to listen to students as they speak and paraphrase their responses wherever necessary. As students identify key concerns, trainers should list them on the board for references.

\subsubsection{Understand Your Students}

It will benefit the case facilitator if the background in context of their experiences, exposure and sociocultural orientation of 
the students is known in advance.

I emphasize that a facilitator should know the backgrounds of each student at the planning stage itself so that when you prepare issues on the case, you already have questions to be asked to relevant participants during the discussion. By directing questions on different segments to those that matches the students' background, you will be able to draw synergy in the class for concept clarity and experience sharing in similar fields. If you know students' background, you will have some idea as to who is going to contribute what type of stories and facilitate more discussion.

I remember that RIM used to provide lecturers with a page, almost like a student card, that had photographs and names of the students in each class. I used to collect some critical background information and list them against the name. I would then review each student's background before the course started. I found that system a very handy and useful tool. I would suggest the RIM team to further modify and include slightly more information such as the students' interest areas, and experience, if any against each name.

\subsubsection{Conclude The Class Discussion}

While concluding the session on a case, it is important to summarize the class discussion not only on the contents of the case, but also on the process of analysis that students with differing views have put forward during the class discussion. Points listed on the board during the discussion become very helpful at this stage. As a trainer, we should share our own assessment of the case linking with various issues that came up during discussion. Most cases designed for class discussion do not include a chosen solution. The trainer could share his position on his decision choice or share the decision and the reasons thereof of the protagonist that may be available in the teaching note. Finally, it is helpful to provide trainer's feedback to the students on how the discussion went on and how the groups and individuals interacted. Such a feedback mechanism helps improve the case discussion in future.

\subsubsection{Evaluate Performance}

To motivate students to come prepared for the class and to encourage them to be attentive during the discussion, the trainer may choose to grade the class participation in terms of quantity and quality during the session itself. You may like to at least keep some kind of record for each session as reminders to facilitate your objectivity in evaluation at a later date.

I used student's performance cards to facilitate o grading both individually and group-wise. If you have students' photographs and some detail, this will break the communication barriers quite early on and make it easier to maintain performance records. At RIM by using the student card system, I could maintain some indication as to who participated and who did not, who contributed meaningfully and who simply talked without much substance, and who helped in creating value for the class and who disrupted the class. In fact, I used to provide individual students and groups with class participation feedback very frequently during the course term based on my records.

Since my course used to be mixed with lecture, discussion and case studies and the class was large, I had to break them into groups. I used to divide students into different groups ensuring representation from different background in terms of their academic background, experience etc. This helped balance the group composition.

Practicing instant evaluation of individuals and groups based on their class contribution reduces disparity in the overall performance ratings of the students and keeps the class motivated. So, it is quite handy to have the student cards and group cards for maintaining records of student's class participation.

\subsubsection{Allow Peer Evaluation}

Peer pressure learning is one of the main aims of the group works. More often than not, a case method teaching practices group learning, which has several advantages over individual learning process. A group approach helps students build their personality in terms of people management skills, communication skills, managing differences and so on. As the case study intends to provide more practical and real life learning, it is only appropriate to help students work in groups since in real workplaces everyone has to be in groups. However, I did observe like any trainer may have, that there is always some free riders looking for free lunch while working in a group. They know that few sincere and hardworking students in their group will get the group work done. Unless an evaluation system is put in place that discourages free riders, the aim of learning equity in the class will be defeated. To address such disadvantages of the group learning process, many trainers practice a peer evaluation system. At least among Bhutanese students, most often than not, I did not find even the peer evaluation system to be an effective solution to the free riders problem. I noticed that everyone in the group would give similar ratings to all peer members irrespective of their individual contribution.

To overcome this problem I practiced a different formula. I made it clear to the students in the group that everyone has to equally participate and be equally prepared for the class discussion. In some cases where there used to be a group presentation, I reserved the right to call anyone from the group to make the presentation and direct questions randomly to any member. I asked anyone to open the case and lead the class. If a member has been a free rider, $\mathrm{s} /$ he is caught. Then allow the opportunity to other members in the group to speak. Obviously, those who have put in an effort will have substance. That way, the nonparticipants in the group may be identified and accordingly rated. Further, to ensure that the group members put pressure on their peers, an overall group rating was done based on 
the overall performance of the members in the group. This discouraged them to some extent from giving same ratings to all their peers. This process of student evaluation will probably work better for all types of group work and not just for the case studies.

I remember that during the conference in Samtse, Prof. M. K. Ingale of Gaedu College of Business Studies sharing his experience of dealing with free riders problem. He stated that he divides a group into two sub-groups with two to three students and during the case presentation by the group one has to do the case opening and address the general queries from the students in the class, whereas the other group is required to answer specific questions that he asked them as the teacher. He then rated the performance of both the subgroups, took an average of the two to award the final group rating. This way, he found that every member needed to work and peer pressure to contribute equally functioned well. I feel his strategy could work well in the Bhutanese setting.

\section{CONLUSION}

As a concluding note, I would like to emphasize that the case method in teaching overcomes the disadvantages of the lecture method, which is characterized by almost a one-way information flow with the trainer at the center. The case approach puts the students at the center of the learning process. They are given more responsibilities for their own learning. Case studies prepare students more practically for work places as independent thinkers with open minds, capable of understanding group dynamics, better time managers, good communicators, information seekers and analyzers, capable of problem diagnosis, challengers with their own point of views and rationale in terms of decisionmaking and problem solving. It is high time that our educational institutions of higher learning in Bhutan starts putting more emphasis on case based learning. It is probably due to the predominance of the lecture-based and pre-identified text based teaching and learning system followed by a rigid student evaluation system that our teachers do not see much need to develop cases that address the skill requirement in the job markets. While at RIM I used cases that were available from different sources as our own local cases were hard to be found. Appropriate cases should have theoretical aspects that suit the course objective, local contextual aspects that address local problems and time aspects that keep students informed with recent past and current situations. Obviously, a case written in western cultural context will be difficult and less motivating for Bhutanese students. In the absence of case development capability currently at the colleges and the institutions in our country, we can still use reports, newspaper stories, TV clips on discussion and debates, etc. even if these are poor substitutes. Another substitute to a written case study is to collaborate with relevant industries and request experienced practitioners to come and narrate their practical stories in appropriate times for relevant subject matters.

In the Bhutanese job markets, employers would like to see some familiarities by the job seekers about the local industries in their field of studies. For example, an electrical engineer will be appreciated if he has some knowledge about the broad mandates, functions, business product lines and pricing policies of the electricity companies and related organizations like Druk Green Power Corporation, Bhutan Power Corporation, and Bhutan Electricity Authority etc. They will be further appreciated if they have information and knowledge on what types, how many, in which locations, with what capacities, with what kind of funding mechanisms the power projects are being implemented and are in the pipelines. Similarly, a graduate in business management or economics is rated higher in his job interview if he is knowledgeable about the business aspects and economics of Bhutanese industries and firms, and national economic strengths and problems. It is not sufficient just to have some theoretical knowledgeable on what it means by fiscal and monetary policies but one has to understand what types of policies are in place in Bhutan under each category and how effectively they are working. Case approach of teaching prepares students not only on localized practical contents but also develops them in terms of analytical, communication and leadership skills. Either the developed local cases in these areas or the use of published reports from relevant organizations or inviting relevant practitioners from these areas to supplement the traditional lectures will go a long way in adding value to our graduates. Kharka (2011) states that the collaboration between Bhutanese institutes of higher learning and the local industries should be pursued to make our learning more practical.

\section{ACKNOWLEDGEMENTS}

I thank all the participants of the "research informed teaching" workshop at Samtse College of Education organized by the Royal Bhutan University (RUB)in October 2014 for their valuable comments. My special thanks to Ms. Tshering Denka, an analyst at the Druk

Holding and Investments, Bhutan for her the editorial assistance.

\section{REFERENCES}

1. Barkley, E. F, Cross, K. P. \& Major, C. H. (2005), Collaborative Learning Techniques: A Handbook for College Faculty, San Francisco: Jossey-Bass, available at http://www.cmu.edu/teaching/.

2. Goodenough, D. A. (1994), "Speaking of Teaching", Stanford University Newsletter on Teaching, Vol. 5, No. 2.

3. Golich, V. L, Boyer, M, Franko, P. and Lamy, S. (2000), "The ABCs of Case Teaching", Institute for Study of Diplomacy, Georgetown University, available at www.guisd.org.

4. Ingale, M.K (2014), "Writing an Appropriate Case Study", Conference Bulletin on Research Informed Teaching, Royal University of Bhutan.

5. Kharka, D.S. (October, 2011), "Institute of Higher Learning and Corporate World: need for collaboration”, DHI Melong, Druk Holding and Investments, Thimphu Bhutan. 


\section{ISSN 2278-5612}

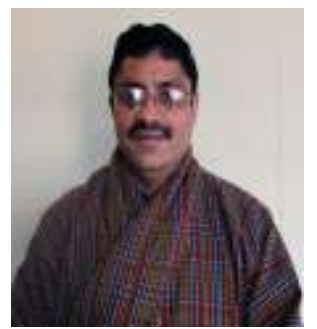

\section{Dr. Damber Singh Kharka}

Dr. Damber Singh Kharka works as the Officiating CEO and Director at Druk Holding and Investments, Bhutan. He holds a MA degree in Economics from the University of New Brunswick in Canada and a PhD from Haryana School of Business, GJUS\&T in India. He has substantial experience in training, consulting and research in different disciplines of management as a result of his nineteen years academic career at the Royal Institute of Management. Besides having provided consulting and training services for several years, he also has to his credit many papers published in national, regional and international publications. He very successfully transited from the world of academia to the corporate sector. Dr. Kharka has been the key initiator for development and implementation of corporate governance and performance management systems in the $\mathrm{DHI}$ subsidiaries and possesses rich experience as a board director in a number of companies.

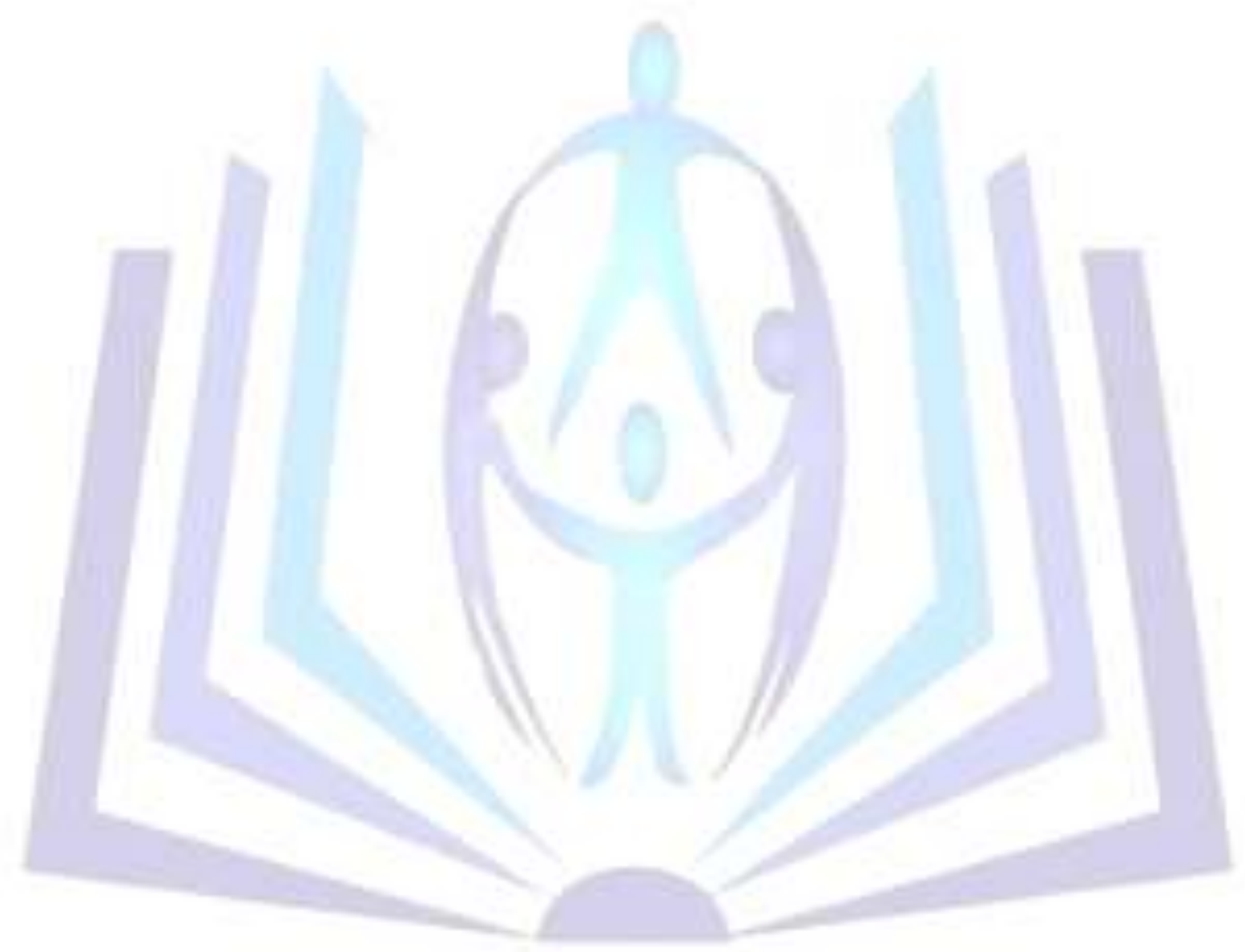

